\title{
Increased Cortical Nitric Oxide Release After Phencyclidine Administration
}

\author{
ERIK PÅLSSON, ${ }^{1,2 *}$ NIALL FINNERTY, ${ }^{2}$ KIM FEJGIN, ${ }^{1}$ DANIEL KLAMER, ${ }^{1}$ CAROLINE WASS, ${ }^{3}$ \\ LENNART SVENSSON, ${ }^{1}$ AND JOHN LOWRY ${ }^{2}$ \\ ${ }^{1}$ Department of Pharmacology, Institute of Neuroscience and Physiology, Sahlgrenska Academy at \\ University of Gothenburg, Göteborg, Sweden \\ ${ }^{2}$ Department of Chemistry, National University of Ireland Maynooth, Maynooth, Ireland \\ ${ }^{3}$ Forensic Psychiatry, Institute of Neuroscience and Physiology, The Sahlgrenska Academy at \\ University of Gothenburg, Gothenburg, Sweden
}

\begin{abstract}
KEY WORDS rat; schizophrenia; in vivo voltammetry; cognition
ABSTRACT Phencyclidine exerts psychotomimetic effects in humans and is used as a pharmacological animal model for schizophrenia. We, and others, have demonstrated that phencyclidine induces cognitive deficits in rats that are associated with schizophrenia. These cognitive deficits can be normalized by inhibition of nitric oxide synthase. The development of selective microelectrochemical nitric oxide sensors may provide direct evidence for the involvement of nitric oxide in these effects. The aim of the present study was to use LIVE (long term in vivo electrochemistry) to investigate the effect of phencyclidine, alone or in combination with the nitric oxide synthase inhibitor L-NAME, on nitric oxide levels in the medial prefrontal cortex of freely moving rats. Phencyclidine $\left(2 \mathrm{mg} \mathrm{kg}{ }^{-1}\right)$ produced an increase in cortical nitric oxide levels and this increase was ameliorated by L-NAME $\left(10 \mathrm{mg} \mathrm{kg}^{-1}\right)$. Tentatively, the results from the present study provide a biochemical rationale for the involvement of nitric oxide in the phencyclidine model of schizophrenia. Synapse 63:1083-1088, 2009. 2009 Wiley-Liss, Inc.
\end{abstract}

\section{INTRODUCTION}

Nitric oxide (NO) is an unstable free radical gas, and accumulated data suggest a pleiotropic role of NO in physiological and pathophysiological mechanisms both centrally and peripherally (Snyder and Ferris, 2000). Interestingly, a number of studies have suggested that NO might play an important role in the action of the psychotomimetic NMDA-receptor antagonist phencyclidine (PCP). Administration of PCP to laboratory animals is commonly used to model certain aspects of schizophrenia. The rationale for this is that PCP can induce a state in humans that closely resembles schizophrenia, encompassing both positive and negative symptoms as well as cognitive dysfunctions (Javitt, 2007; Luby et al., 1959). It has been previously demonstrated that a wide range of translational PCP-induced effects, including impairments in preattentive information processing, nonassociative learning, selective attention, spatial learning, spatial reference memory, working memory, and cognitive flexibility can all be prevented by interfering with the production of NO (Johansson et al., 1997; Klamer et al., 2001, 2004, 2005c; Wass et al., 2006a,b). These findings suggest that the schizophrenia-like behavioral effects of PCP in rodents are, at least in part, mediated by an increase in NO activity. This is supported by a recent study showing a NO-dependent increase in cGMP signaling, a main effector of $\mathrm{NO}$ in the brain, in the mouse prefrontal cortex following PCP-administration (Fejgin et al., 2007). Furthermore, blocking the production of cGMP in the prefrontal cortex prevented a PCPinduced deficit in preattentive information processing (Fejgin et al., 2007). In addition, a number of clinical

Erik Pålsson, Niall Finnerty, and Kim Fejgin contributed equally to this work. Contract grant sponsor: the Swedish Medical Research Council; Contract grant number: 4247; Contract grant sponsors: Adlerbertska Forskningsstiftelsen, AstraZeneca Sweden, Wilhelm och Martina Lundgrens Vetenskapsfond, Hjärnfonden, Jubileumsfonden, Konrad och Helfrid Johanssons fond, The Lundbeck Foundation, the Royal Society of Chemistry (Analytical Division), Schizofrenisällskapet, Stiftelsen Goljes Minne, Stiftelsen Tornspiran, Svenska Läkarsällskapet (the Swedish Society of Medicine), Svenska Sällskapet för Medicinsk Forskning (the Swedish Society for Medical Research), Ảhlen-stiftelsen and Åke Wibergs Stiftelse.

*Correspondence to: Erik Pålsson, Department of Pharmacology, The Institute of Neuroscience and Physiology, Sahlgrenska Academy at the University of Gothenburg, POB 431, SE 40530 Göteborg, Sweden.

E-mail: erik.palsson@pharm.gu.se

Received 18 August 2008; Accepted 31 March 2009

DOI 10.1002/syn.20690

Published online in Wiley InterScience (www.interscience.wiley.com). 
studies suggest that aberrations in NO signaling may be involved in the pathophysiology of schizophrenia (for a review see Bernstein et al., 2005). Taken together, these observations suggest that the NO pathway may constitute an interesting target for novel pharmacological therapies in schizophrenia and possibly play a role in the pathophysiology of the disorder. However, this contention rests on indirect evidence as suitable tools for the real-time detection of NO in vivo have, until recently, been lacking. In the present study, the role of NO signaling in the behavioral and biochemical effects of PCP was further investigated using a novel NO-sensitive microelectrochemical sensor. The sensor enables the recording of real-time NO levels in awake, freely moving animals. In the first experiment (denoted as Experiment 1, Department of Chemistry, National University of Ireland, Maynooth) rats were systemically treated with PCP to investigate a possible effect on NO levels in the medial prefrontal cortex. The prefrontal cortex was chosen based on its proposed role in the cognitive dysfunction associated with schizophrenia (Lewis and Moghaddam, 2006) and previously published findings (Fejgin et al., 2007). In a second experiment (denoted as Experiment 2, Department of Pharmacology, University of Gothenburg, Sweden), the dose-dependency of this effect was studied. Finally, in a third experiment (denoted as Experiment 3, Department of Pharmacology, University of Gothenburg, Sweden) the effect of pretreatment with the nitric oxide synthase (NOS)-inhibitor, NG-nitro-L-arginine methyl ester (L-NAME), on PCP-induced changes in NO-levels in the prefrontal cortex was investigated.

\section{METHODS Animals}

Male Wistar rats (UCD, Ireland, 280-400 g) were used in Experiment 1 and male Sprague-Dawley rats (Taconic, Denmark, 280-400 g) were used in Experiments 2 and 3 . All animals were housed, with a maximum of four per cage, in a colony room under constant temperature $\left(20^{\circ} \mathrm{C} \pm 1^{\circ} \mathrm{C}\right)$ and humidity $(50 \% \pm$ $5 \%$ ). Food and water were available ad libitum. The daylight cycle was maintained artificially (lights on from 0600 to $1800 \mathrm{~h}$ ), and the experiments were conducted during the light phase. The animals were allowed to acclimatize for at least 1 week prior to surgery. All experimental procedures used in the present study were approved by the National University of Ireland Maynooth Ethics Committee (Animal Experimentation) and the Ethics Committee for Animal Experiments, Goteborg, Sweden respectively.

\section{Drugs}

Phencyclidine hydrochloride (PCP, Sigma Chemicals, St Louis, MO) and L-NAME (RBI, Natick, USA) were used in the present study. PCP and L-NAME were dissolved in saline $(0.9 \% \mathrm{NaCl})$ and injected subcutaneously (s.c.) in a volume of $2 \mathrm{ml} \mathrm{kg}^{-1}$. The doses of PCP and L-NAME used were based on previously published studies (Johansson et al., 1997; Klamer et al., 2005c; Wass et al., 2006a).

\section{Surgical procedure}

The rats were anesthetized with isoflurane, placed in a Kopf stereotaxic instrument and kept on a heating pad to prevent hypothermia. An incision was placed down the midline of the skull and the bone was exposed. Four holes for the anchor screws, two holes for the reference ( $8 \mathrm{~T} \mathrm{Ag}$ wire, $200-\mu \mathrm{m}$ bare diameter; Advent Research Materials, UK) and auxiliary (8T Ag wire) electrodes, and one or two holes for the sensor electrodes were drilled. Electrodes were then implanted following a previously described procedure (Lowry et al., 1997). The coordinates used for the medial prefrontal cortex relative to bregma were as follows: anterior $+3.2 \mathrm{~mm}$, lateral to midline \pm 0.8 $\mathrm{mm}$, and ventral -5.2 (Experiment 1) or -4.2 (Experiments 2 and 3) mm from the brain surface. The electrodes were inserted into the brain and connected to a pedestal that was secured to the anchor screws with dental cement. During surgery, the rats were administered $2.0 \mathrm{ml}$ of saline, to reduce postoperative dehydration and an analgesic (buprenorphine or carprofen) to reduce postoperative pain. The animals were allowed to recover for 2-4 days before commencing experiments. They were housed individually in standard plastic cages.

\section{Electrochemical detection of NO}

Prefrontal cortex NO levels were determined using a NO selective amperometric microsensor. The microsensor is a Nafion ${ }^{\circledR}$-modified Pt disk electrode (patent no. S2007/00,774). The sensor design has been validated for in vitro and in vivo NO sensitivity (Brown et al., 2005; Finnerty, 2008) and in vitro selectivity against ascorbic acid, uric acid, and dopamine (Brown and Lowry, 2003). The NO oxidation current (electrode potential of $+0.90 \mathrm{~V}$ against a $\mathrm{Ag}$ reference electrode) was detected using a low-noise potentiostat (Experiment 1: ACM Instruments, United Kingdom; Experiment 2: Biostat II, Electrochemical and Medical Systems, UK) and converted using an $\mathrm{A} / \mathrm{D}$ converter (PowerLab, ADInstruments, United Kingdom). The digital signal was then recorded using Chart software (v5, ADInstruments) running on a PC. Individual sensors were tested for ascorbic acid interference and calibrated to ensure NO sensitivity in vitro prior to surgery. Each animal was connected to the in vivo voltammetry equipment on the day before an experiment to allow the NO oxidation current to reach a stable baseline. All experiments were carried out with the animal in its home cage. For Experiment 1, two or 
four sensors were implanted bilaterally in the prefrontal cortex of five rats (total sensor $n=12$, right hemisphere $n=6$, left hemisphere $n=6$ ). After recovery the animal was subjected to $\mathrm{PCP}\left(2 \mathrm{mg} \mathrm{kg}{ }^{-1}\right)$ treatment. Saline was administered prior to PCP (2 $\mathrm{mg} \mathrm{kg}{ }^{-1}$ ) to control for effects related to the injection procedure. For Experiment 2, two sensors were implanted in the prefrontal cortex of four rats. After recovery each animal was subjected to four-drug treatments with a 2-day washout period between each treatment. The drug treatments were saline, PCP (1 $\left.\mathrm{mg} \mathrm{kg}{ }^{-1}\right), \operatorname{PCP}\left(2 \mathrm{mg} \mathrm{kg}^{-1}\right)$, and PCP (4 mg kg$\left.{ }^{-1}\right)$ and the order of the drug combinations was varied between animals in a semirandomized manner. Finally for Experiment 3, one sensor was implanted unilaterally (the number of animals was balanced with respect to right and left hemisphere) in the prefrontal cortex of eight rats. After recovery each animal was subjected to four-drug treatment combinations with a 2-day washout period between each treatment. The drug combinations were saline + saline, L-NAME $(10 \mathrm{mg}$ $\left.\mathrm{kg}^{-1}\right)+$ saline, saline $+\operatorname{PCP}\left(2 \mathrm{mg} \mathrm{kg}{ }^{-1}\right)$, and L-NAME (10 mg kg-1) + PCP $\left(2 \mathrm{mg} \mathrm{kg}^{-1}\right)$. The drug combinations were administered with a 10 -min interval between the two injections and the order of the drug combinations was varied between animals in a semirandomized manner.

\section{Probe placement verification}

After termination of the experiments the rats were decapitated. The brains were removed and fixated (Accustain, Sigma-Aldrich) or frozen at $-80^{\circ}$ C. Sensor placement was verified by sectioning the brains using a vibratome or cryostat and an atlas of the rat brain for reference. All sensors were verified to be positioned within the prelimbic or infralimbic part of the prefrontal cortex at $3.2 \pm 0.4 \mathrm{~mm}$ anterior of bregma.

\section{Data and statistical analysis}

The NO oxidation current over time (sampling rate $4 / s$ ) recorded in chart was used as data. The mean of the sampling period ( $\sim 5 \mathrm{~min})$ immediately prior to drug treatment was used as a baseline. For Experiments 1 and 3, the mean current change from baseline was calculated for a 5-min sampling period surrounding the time points of 30,60 , and 90 min after injection. This time frame was chosen to facilitate comparison with previously published behavioral studies (Johansson et al., 1997; Klamer et al., 2005b; Wass et al., 2006a). For Experiment 2, the area under the curve for a 180-min time period following drug administration was calculated using GraphPad software. To investigate whether the drug treatments had any significant effect on NO levels, one or two way analysis of variance (ANOVA) was performed as specified in the Results section. The ANOVAs were followed by Bonferroni's test for comparisons between groups where appropriate. Two tailed levels of significance were used and $P<0.05$ was considered statistically significant. Additionally, data from the left and right hemisphere were compared in Experiment 1 using an unpaired $t$ test to investigate a potential difference in NO response after PCP treatment. Since the two experiments used different strains of rats an unpaired $t$ test was performed to control for an effect of strain in the effects of PCP on NO levels.

\section{RESULTS \\ Experiment 1}

Systemic administration of PCP resulted in a prolonged increase in NO release in the prefrontal cortex (Fig. 1A). Analysis of the NO oxidation current change during the sampling period $60 \mathrm{~min}$ after PCP administration did not reveal a significant difference between the left and right hemisphere. Consequently, the data were pooled for further analysis. A one-way repeated measures ANOVA with treatment as within subjects factor revealed a significant increase in NO levels after PCP $\left(2 \mathrm{mg} \mathrm{kg}^{-1}\right)$ administration $(F(3,11)$ $=15.633, P<0.001$, Fig. 1B). The Bonferroni test showed that all the three time points (30, 60, $90 \mathrm{~min})$ following PCP administration were significantly different to the saline condition $(P<0.001, P<0.01$, and $P<0.01$, respectively).

\section{Experiment 2}

Similar to Experiment 1, PCP induced an increase in NO levels. Analysis of the AUC for $180 \mathrm{~min}$ (Fig. 2) following drug administration using a oneway repeated measures ANOVA with dose (0, 1, 2, and $4 \mathrm{mg} \mathrm{kg}^{-1}$ ) as within subjects factor revealed a significant dose-dependency of the PCP effect $(F(3,18)$ $=6.957, P<0.01)$. The following Bonferroni test showed that the PCP (2 mg kg $\left.{ }^{-1}\right)$ AUC was significantly different to saline $(P<0.05)$.

\section{Experiment 3}

As in Experiment 1, PCP induced an increase in NO levels (Fig. 3A). The mean increase in NO levels after PCP treatment (at $60 \mathrm{~min}$ ) was lower in Experiment $2(22 \pm 10 \mathrm{pA})$ compared to Experiment $1(48 \pm$ $37 \mathrm{pA}$ ), although the difference did not quite reach statistical significance (unpaired $t$ test, $t=-1.903$, df $=18, P=0.073)$. The observed increase in NO oxidation current was ameliorated by pretreatment with L-NAME, which in itself reduced NO levels. A twoway repeated measures ANOVA with time and treatment as within subjects factors revealed a main effect of time $(F(2,7)=4.499, P<0.05)$, treatment $(F(3,7)$ $=12.064, P<0.001)$ and an interaction between time and treatment $(F(6,7)=2.682, P<0.05)$. Given this 

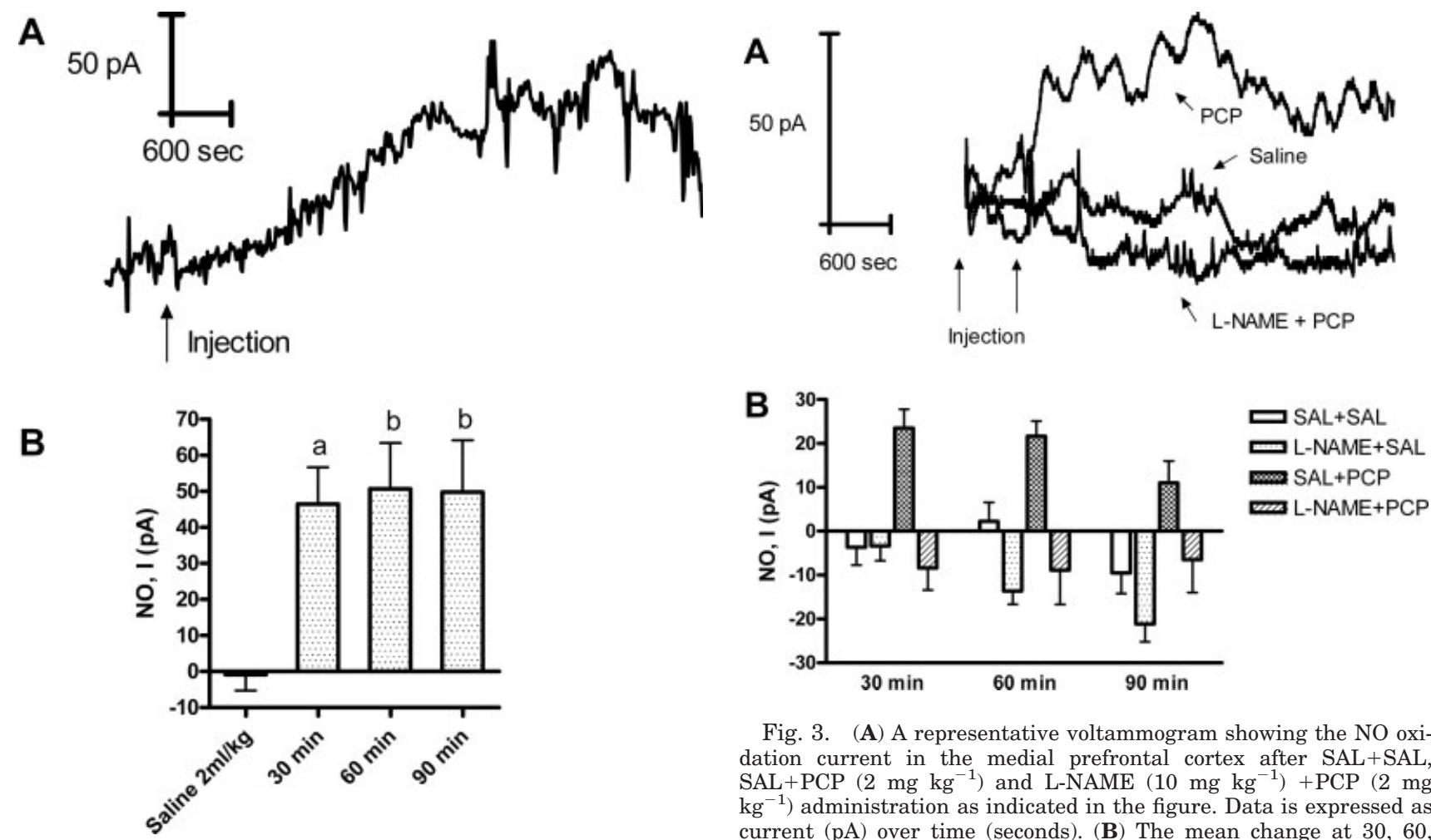

Fig. 3. (A) A representative voltammogram showing the NO oxidation current in the medial prefrontal cortex after SAL + SAL SAL+PCP $\left(2 \mathrm{mg} \mathrm{kg}^{-1}\right)$ and L-NAME $\left(10 \mathrm{mg} \mathrm{kg}^{-1}\right)+\mathrm{PCP}(2 \mathrm{mg}$ $\mathrm{kg}^{-1}$ ) administration as indicated in the figure. Data is expressed as current ( $\mathrm{pA}$ ) over time (seconds). (B) The mean change at 30,60, and $90 \mathrm{~min}$ in prefrontal cortex NO levels as compared to baseline in eight rats (sensor $n=8$ ). All animals received each treatment in a semirandomized order with a 2-day washout period between each drug combination (saline + saline, L-NAME + saline, saline + PCP and L-NAME + PCP). Data is expressed as mean \pm SEM current change (pA) over a 5-min sampling period at 30,60 , and 90 min afdation 1. (A) A representative voltammogram showing the $\left.\mathrm{kg}^{-1}, t=0\right)$ administration. Data is expressed as current ( $\mathrm{pA}$ ) over time (seconds). (B) The mean change at 30,60 , and $90 \mathrm{~min}$ in medial prefrontal cortex NO levels after PCP $\left(2 \mathrm{mg} \mathrm{kg}^{-1}, t=0\right)$ administration as compared to saline administration in five rats (sensor $n=12$ ). Data is expressed as mean \pm SEM current change (pA) after saline administration or the mean of a 5-min sampling period at 30,60 , and 90 min after PCP administration. a, $P<0.001$ and $\mathrm{b}, P<0.01$ vs. saline.

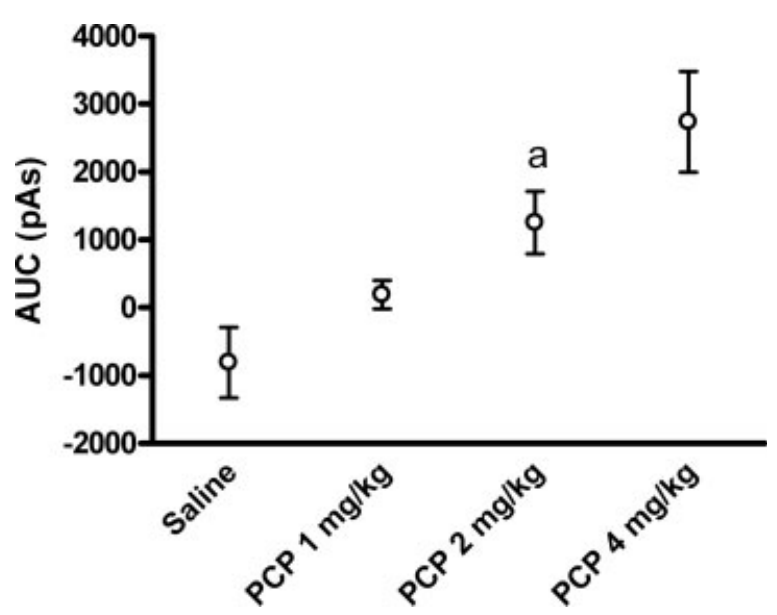

Fig. 2. The NO oxidation current AUC for a 180-min time period medial after saline and PCP (1, 2, and $\left.4 \mathrm{mg} \mathrm{kg}^{-1}\right)$ administration in four rats (sensor $n=7$ ). All animals received each treatment in a semirandomized order with a 2-day washout period between each drug administration. Data is expressed as mean \pm SEM AUC (pAs) as compared to baseline. a $P<0.05$ vs. saline. interaction, each time point $(30,60,90 \mathrm{~min})$ was analyzed separately using a two-way repeated measures ANOVA with pretreatment (saline or L-NAME) and treatment (saline or PCP) as within-subject factors. For the 30-min sampling period (Fig. 3B) the ANOVA revealed a main effect of pretreatment $(F(1,7)=$ 14.992, $P<0.01)$, treatment $(F(1,7)=8.944, P<$ 0.05 ) and a significant interaction between pretreatment and treatment $(F(1,7)=16.565, P<0.01)$. The analysis of the 60-min sampling period (Fig. 3B) on the other hand showed a main effect of pretreatment $(F(1,7)=15.830, P<0.01)$ and treatment $(F(1,7)=$ 9.838, $P<0.05)$ but no significant interaction between the factors. Similarly, the ANOVA for the 90min sampling period (Fig. 3B) showed a main effect of pretreatment $(F(1,7)=8.150, P<0.05)$ and treatment $(F(1,7)=7.220, P<0.05)$ but again no significant interaction between the factors was found.

\section{DISCUSSION}

An important finding of the present study was that the psychotomimetic drug, PCP, was found to induce 
a dose-dependent increase in brain NO levels, thus corroborating previous indirect evidence of this effect of PCP. In addition, the PCP-induced elevation of NO could be counteracted by pretreatment with the NOS inhibitor, L-NAME, in a dose that has previously been shown to block the behavioral effects of PCP in translational animal models of schizophrenia (Johansson et al., 1997; Klamer et al., 2005c; Wass et al., 2006a,b).

There was a trend $(P=0.10)$ towards a higher increase in NO after PCP treatment in Experiment 1 compared to Experiment 2. This may be an effect of strain or due to the difference in sensor placement and future experiments may clarify this. However, PCP induced an increase in NO levels in both Wistar and Sprague-Dawley rats, which shows that this effect of PCP is not restricted to a specific strain of rats only. In vitro calibration data indicate that the observed mean increase in NO levels was $\sim 24 \mathrm{nM}$ in Experiment 1 and $\sim 13 \mathrm{nM}$ in Experiment 2. This increase is substantial compared to estimated NO levels of $0.1 \mathrm{nM}$ (reviewed in Hopper and Garthwaite, 2006). This value is derived from a different methodological approach, but it may be that extracellular NO levels in the brain may be higher than previously estimated. However, it should also be noted that the calculated NO levels in the present study are derived from in vitro precalibration data and it remains to be shown that this fully equates the in vivo changes in NO oxidation current. Additionally, the relationship between the changes in NO observed in the present study and synaptic NO levels is unclear. Synaptic levels of NO are thought to be in the very low nanomolar range (reviewed in Garthwaite, 2008). Given the amplitude and sustained effect on NO levels, the present observations may be more related to neurovascular or volume transmission effects of NO rather than events occurring at discrete synapses. Importantly, several genetic and biochemical studies support the involvement of NO, and downstream NOsignaling in the form of cGMP, in the behavioral effects of PCP. Mice lacking the NOS-1 (Bird et al., 2001; Klamer et al., 2005a) or PDE-1 (Siuciak et al., 2007) genes display an altered sensitivity to the behavioral effects of PCP. In addition, PCP shows an increased cGMP production both in vitro (Vesely, 1979) and in vivo (Fejgin et al., 2007). Interestingly, a recent study demonstrated a prolonged NO increase of $\sim 8 \mathrm{nM}$ in the medial prefrontal cortex following cocaine administration in anesthetized rats (Sammut and West, 2008). This implies that an increase in NO levels may be a common denominator of psychostimulants; a notion that warrants further experiments.

The effect over time curves in the present study (see Figs. 1 and 3) indicated that the peak effect of PCP on NO levels at least partially overlaps with the effect on preattentive information processing as shown in previous studies (Klamer et al., 2005b), suggesting a temporal correlation of increased NO levels and deficits in preattentive information processing following systemic PCP administration in rats. However, the mechanism by which PCP increases brain NO levels remains to be determined. Increased activity of NOS-1 (see below) in the brain has been coupled to NMDA-receptor activation and subsequent $\mathrm{Ca}^{2+}$ influx. Logically, this source of $\mathrm{Ca}^{2+}$ cannot explain the present effects as PCP is a potent NMDAreceptor antagonist (Javitt, 2007). However, it has been shown that PCP can induce an increased release of glutamate in the frontal cortex of rats (Adams and Moghaddam, 2001). This could lead to an activation of AMPA receptors permeable to $\mathrm{Ca}^{2+}$ and a subsequent AMPA receptor-mediated NO production (Fedele and Raiteri, 1999; Zhou et al., 2006).

L-NAME in a dose of $10 \mathrm{mg} \mathrm{kg}{ }^{-1}$ has been shown to block a number of PCP-induced behavioral effects in rats, including a deficit in prepulse inhibition, hyperactivity, abnormal latent inhibition and deficits in spatial learning and working memory (Johansson et al., 1997; Klamer et al., 2005c; Wass et al., $2006 \mathrm{a}, \mathrm{b})$. The present study provides a biochemical rationale for these effects as PCP induced an increase in NO levels and that effect was attenuated by pretreatment with L-NAME in a dose of $10 \mathrm{mg} \mathrm{kg}{ }^{-1}$. This dose of L-NAME also lowered NO levels by itself. The absence of a significant pretreatment $\times$ treatment interaction at the 60 - and 90 -min sampling periods suggest that the effect of L-NAME on the PCPinduced increase in NO levels may be best explained as a combination of a true interaction and an additive effect. Thus, it may be that L-NAME and PCP exert their opposing effects on NO levels partly via different signaling pathways. However, the analysis of the 30-min sampling period showed a significant pretreatment $\times$ treatment interaction which implies a functional connection via the NO system. In addition, L-NAME has been shown to block a PCP-induced increase in cGMP levels in the prefrontal cortex of mice, without affecting baseline cGMP levels (Fejgin et al., 2007).

In summary, the present study demonstrates a long-lasting PCP-induced release of NO in the brain of awake, freely moving animals. Thus, this study provides the first direct biochemical evidence for an involvement of NO in the effects of PCP. This has previously been suggested though behavioral pharmacology data and indirect measures of NO activity (Fejgin et al., 2007; Klamer et al., 2005b). In addition, the present results indicate that a PCP-induced increase in NO levels can be attenuated by the NOS-inhibitor L-NAME, in a dose that has been shown to be effective in ameliorating schizophrenia-related behavioral effects of PCP. This suggests that the ability of L-NAME to block PCP-induced behavior is directly 
related to an additive effect on NO levels by the two compounds. This highlights the potential of the NO pathway as a future target for novel treatment rationales in schizophrenia.

\section{ACKNOWLEDGMENTS}

The authors gratefully acknowledge the technical assisstance of Joseph Fernando and helpful discussions with Dr. Jeffrey C. Glennon.

\section{REFERENCES}

Adams BW, Moghaddam B. 2001. Effect of clozapine, haloperidol, or M100907 on phencyclidine-activated glutamate efflux in the prefrontal cortex. Biol Psychiatry 50:750-757.

Bernstein HG, Bogerts B, Keilhoff G. 2005. The many faces of nitric oxide in schizophrenia. A review. Schizophr Res 78:69-86.

Bird DC, Bujas-Bobanovic M, Robertson HA, Dursun SM. 2001. Lack of phencyclidine-induced effects in mice with reduced neuronal nitric oxide synthase. Psychopharmacology (Berl) 155: 299-309.

Brown FO, Lowry JP. 2003. Microelectrochemical sensors for in vivo brain analysis: An investigation of procedures for modifying $\mathrm{Pt}$ electrodes using Nafion. Analyst 128:700-705

Brown FO, Finnerty NJ, Bolger FB, Millar J, Lowry JP. 2005. Calibration of NO sensors for in-vivo voltammetry: Laboratory synthesis of NO and the use of UV-visible spectroscopy for determining stock concentrations. Anal Bioanal Chem 381:964-971.

Fedele E, Raiteri M. 1999. In vivo studies of the cerebral glutamate receptor/NO/cGMP pathway. Prog Neurobiol 58:89-120.

Fejgin K, Palsson E, Wass C, Svensson L, Klamer D. 2007. Nitric oxide signaling in the medial prefrontal cortex is involved in the biochemical and behavioral effects of phencyclidine. Neuropsychopharmacology 33:1874-1883.

Finnerty NJ. 2008. Electrochemical Sensors: In-vitro and in-vivo analysis of brain nitric oxide and regional cerebral blood flow. $\mathrm{PhD}$ Thesis. Maynooth: National University of Ireland Maynooth.

Garthwaite J. 2008. Concepts of neural nitric oxide-mediated transmission. Eur J Neurosci 27:2783-2802.

Hopper RA, Garthwaite J. 2006. Tonic and phasic nitric oxide signals in hippocampal long-term potentiation. J Neurosci 26:1151311521.

Javitt DC. 2007. Glutamate and Schizophrenia: Phencyclidine. $N$ methyl-D-aspartate receptors, and dopamine-glutamate interactions. Int Rev Neurobiol 78:69-108.

Johansson C, Jackson DM, Svensson L. 1997. Nitric oxide synthase inhibition blocks phencyclidine-induced behavioural effects on pre- pulse inhibition and locomotor activity in the rat. Psychopharmacology (Berl) 131:167-173.

Klamer D, Engel JA, Svensson L. 2001. The nitric oxide synthase inhibitor. L-NAME, block phencyclidine-induced disruption of prepulse inhibition in mice. Psychopharmacology (Berl) 156:182-186.

Klamer D, Palsson E, Revesz A, Engel JA, Svensson L. 2004. Habituation of acoustic startle is disrupted by psychotomimetic drugs: Differential dependence on dopaminergic and nitric oxide modulatory mechanisms. Psychopharmacology (Berl) 176:440-450.

Klamer D, Engel JA, Svensson L. 2005a. Effects of phencyclidine on acoustic startle and prepulse inhibition in neuronal nitric oxide synthase deficient mice. Eur Neuropsychopharmacol 15:587-590.

Klamer D, Palsson E, Fejgin K, Zhang J, Engel JA, Svensson L. 2005 b. Activation of a nitric-oxide-sensitive cAMP pathway with phencyclidine: elevated hippocampal cAMP levels are temporally associated with deficits in prepulse inhibition. Psychopharmacology (Berl) 179:479-488.

Klamer D, Palsson E, Wass C, Archer T, Engel JA, Svensson L. 2005c. Antagonism of the nitric oxide synthase inhibitor. L-NAME, of the effects of phencyclidine on latent inhibition in taste aversion conditioning. Behav Brain Res 161:60-68.

Lewis DA, Moghaddam B. 2006. Cognitive dysfunction in schizophrenia: Convergence of gamma-aminobutyric acid and glutamate alterations. Arch Neurol 63:1372-1376.

Lowry JP, Boutelle MG, Fillenz M. 1997. Measurement of brain tissue oxygen at a carbon paste electrode can serve as an index of increases in regional cerebral blood flow. J Neurosci Methods 71:177-182.

Luby ED, Cohen BD, Rosenbaum G, Gottlieb LS, Kelly R. 1959. Study of a new schizophrenomimetic drug-sernyl. Arch Neurol Psychiatry 81:363-369.

Sammut S, West AR. 2008. Acute cocaine administration increases NO efflux in the rat prefrontal cortex via a neuronal NOS-dependent mechanism. Synapse 62:710-713.

Siuciak JA, McCarthy SA, Chapin DS, Reed TM, Vorhees CV, Repaske DR. 2007. Behavioral and neurochemical characterization of mice deficient in the phosphodiesterase-1B (PDE1B) enzyme. Neuropharmacology 53:113-124.

Snyder SH, Ferris CD. 2000. Novel neurotransmitters and their neuropsychiatric relevance. Am J Psychiatry 157:1738-1751.

Vesely DL. 1979. Phencyclidine stimulates guanylate cyclase activity. Biochem Biophys Res Commun 88:1244-1248.

Wass C, Archer T, Palsson E, Fejgin K, Alexandersson A, Klamer D, Engel JA, Svensson L. 2006a. Phencyclidine affects memory in a nitric oxide-dependent manner: Working and reference memory. Behav Brain Res 174:49-55.

Wass C, Archer T, Palsson E, Fejgin K, Klamer D, Engel JA, Svensson L. 2006b. Effects of phencyclidine on spatial learning and memory: Nitric oxide-dependent mechanisms. Behav Brain Res 171:147-153.

Zhou Y, Zhou L, Chen H, Koliatsos VE. 2006. An AMPA glutamatergic receptor activation-nitric oxide synthesis step signals transsynaptic apoptosis in limbic cortex. Neuropharmacology 51:67-76. 